\title{
ECOSM-a new joint project for assessing environmental risks of poorly soluble compounds used in cosmetics-project presentation
}

\author{
Stefanie KE Damme ${ }^{1 *}$, Hans-Toni Ratte ${ }^{1}$, Henner Hollert ${ }^{1}$, Anja Coors ${ }^{2}$, Thomas Knacker ${ }^{2}$, Klaus Rettinger ${ }^{3}$, \\ Christoph Schulte ${ }^{4}$ and Andreas Schäffer ${ }^{1}$
}

\begin{abstract}
'Personal Care Products' contain a multitude of substances which introduce certain functions to the product and show a great variability in physicochemical properties. 'Poorly soluble substances', characterised by a low water solubility $(<1 \mathrm{mg} / \mathrm{l})$, may constitute a substantial proportion of these products. Their production volume causes the need for aquatic risk assessment, as requested e.g. by the European Regulation on Registration, Evaluation, Authorisation and Restriction of Chemicals. As it is difficult to conduct toxicity tests at the threshold of the substance's water solubility a high lipophilicity complicates the performance of standardised ecotoxicological tests. For these substances, standard tests mostly provide insufficient results and are often not suitable to assess the risk appropriately. One promising approach to address this problem is the 'poorly solubles approach'. It assumes that highly lipophilic and poorly soluble substances have a low water concentration and consequently might cause low exposure to aquatic organisms. However, as these substances may bioaccumulate high internal exposure might be reached leading to long-term effects. The poorly solubles approach defines an 'ecotoxicological threshold of no concern'. According to the theory, below this concentration, neither acute nor long-term adverse effects on aquatic organisms are expected to occur. This threshold is derived from a comprehensive compilation of experimental data for inert substances with a narcotic mode of action and therefore currently restricted to such substances. Hence, considering this threshold concentration combined with the water solubility of a substance, derived by, e.g. quantitative structure-activity relationships methods, may allow a risk assessment without the need of further experiments. The 'poorly solubles approach' may also become relevant regarding the verification of potential persistent + bioaccumulative + toxic properties. The aim of the project ECOtoxicity investigations of COSMetic ingredients is to develop the 'poorly solubles approach' into a pragmatic tool for risk assessment of the important and environmentally relevant group of highly lipophilic substances with a narcotic mode of action. This project will adapt existing aquatic ecotoxicological test methods using lipophilic compounds to check whether the 'poorly solubles approach' may be useful for risk assessment of such substances.
\end{abstract}

Keywords: cosmetics, ecotoxicity, passive dosing, poorly water-soluble substances, personal care products

\section{Introduction and background}

'Personal Care Products'; also referred to as cosmetic products or cosmetics in the European Union (EU), contain a multitude of chemicals used for different purposes. The chemicals used to introduce certain functions in personal care products show different properties. Due to

\footnotetext{
* Correspondence: stefanie.damme@bio5.rwth-aachen.de

${ }^{1}$ RWTH Aachen University, Institute for Environmental Research (Biology V), Worringerweg 1, 52074 Aachen, Germany

Full list of author information is available at the end of the article
}

some of these properties (e.g. low water solubility) environmental behavior and effects are not easily determined. For many of these substances, ecotoxicological testing is technically not feasible or very expensive. Due to this lack of appropriate testing tools, recent research is increasingly interested in this substance group [1]. 'Poorly soluble substances', which are characterised by low water solubility $(<1 \mathrm{mg} / \mathrm{l})$, may constitute a substantial proportion of the ingredients in some 'personal care products'. Such ingredients with essential function are 
used in numerous cosmetic products, e.g. as emulsifiers. The extensive usage results in high production volumes and thereby requires an assessment of the environmental behavior and the toxicity of these substances to aquatic organisms to fulfill the requirements of the European Registration, Evaluation, Authorisation and Restriction of Chemicals (REACH) Regulation. For manufacturers or importers as responsible registrants, risk assessment is necessary to demonstrate product safety for human health and the environment. At the threshold of the water solubility of the substance, toxicity tests are very difficult to conduct and cannot be performed as a matter of routine. High lipophilicity and high adsorption potential might cause an extensive adsorption of the substance to surfaces, e.g. to the test vessels or test organisms. This might complicate testing procedures, and analytical determination of the substance. As a consequence, the measured concentrations in the test solution are likely to be significantly lower than the nominal concentrations. It also raises difficulties in quantifying the substances with analytical methods because of their low concentration in the water phase. For these reasons standard tests such as the Daphnia acute immobilisation test or the algal growth inhibition test, which are required for the REACH registration, might provide insufficient results and are thereby often not appropriate for a realistic risk assessment.

One approach to solve the problems was suggested by an industry working group in the course of project work for the new EU chemical legislation REACH. The so-called 'poorly solubles approach' [2] is based on the assumption that highly lipophilic and poorly soluble substances have a low concentration in the aqueous phase of waterbodies resulting in a low exposure to aquatic organisms. Subsequent to an extensive analysis of ecotoxicological data, De Wolf et al. [3] proposed a concentration threshold in the aqueous phase, the aquatic exposure threshold of no ecotoxicological concern $\left(\mathrm{ETNC}_{\mathrm{aqu}}\right)$, for inert substances with a narcotic mode of action. For the examined substances with a narcotic mode of action $[4,5]$ it is suggested with a high probability (95 percentile), that neither acute nor long-term adverse effects to aquatic organisms might be expected below this threshold concentration. For inert substances with a narcotic mode of action (baseline toxicity) this threshold was estimated as $\mathrm{ETNC}_{\mathrm{aqu}}=1.9 \mu \mathrm{g} / \mathrm{l}$. Inert chemicals are not reactive when considering overall acute effects and do not interact with specific receptors in an organism and have therefore a narcotic mode of action [5].

The concept of the 'poorly solubles approach' is based on the empirically determined $\mathrm{ETNC}_{\mathrm{aqu}}$-threshold mentioned above. Due to the potential importance of the approach for the ecotoxicological risk assessment of poorly soluble, highly lipophilic organic substances, the project aims to test with selected chemicals whether the $E N_{\text {aqu }}$ concept can be applied to assess the ecotoxicological relevance of such ingredients of personal care products.

Among the number of chemical compounds used in cosmetic products, some with a high lipophilicity (log $K_{\mathrm{OW}}>6$ ) and low biodegradability (not ready biodegradable) may be considered as potential PBT (persistent, bioaccumulative, toxic) or $\mathrm{vPvB}$ (very persistent, very bioaccumulative) substances as defined in REACH, Annex XIII [6]. Because of the low solubility and the experimental challenges, most of these substances have not been satisfactorily tested with regard to their ecotoxicological effects. Due to this, in the first instance, 'passive dosing' methods shall be developed to test the range of ecotoxicity of poorly soluble substances and to gain data for the examination of the 'poorly solubles approach'. The discussed 'poorly solubles approach' may enable a differentiation between substances that have no explicit ecotoxicological relevance and those still requiring further work to reliably assess their PBT properties.

\section{Aims}

The 'poorly solubles approach' as suggested by Tolls et al. [2] might be a promising way forward to address the problems of ecotoxicological testing of some substances with low water solubility and high lipophilicity. As many of these substances are used as ingredients in personal care products, the German Cosmetic, Toiletry, Perfumery and Detergent Association (IKW)-'Industrieverband Körperpflege- und Waschmittel e.V.' (IKW)-has initiated a research project on this topic. Together with the German Federal Environmental Foundation (DBU, Deutsche Bundesstiftung Umwelt) a 3-year study is being supported in the context of a PhD thesis at the Institute for Environmental Research at the Rheinisch-Westfälische Technische Hochschule (RWTH) Aachen University.

This project aims to test the approach's hypotheses and thus, to experimentally investigate the suitability of the 'poorly solubles approach' for certain ingredients in personal care products. The objective implies:

1 . The development and application of suitable experimental methods for the evaluation of a screening method to assess the ecotoxicological relevance of selected poorly soluble substances.

2. The establishment of a method for the risk assessment of highly lipophilic substances without the need of animal testing.

3. The use of the approach for a more reliable assessment of chemicals with potential PBT properties.

The experimental investigation of the poorly solubles approach' with model compounds, which are used in cosmetics, will contribute to substantiate the approach with data. If the substance to be assessed is a potential 
PBT-chemical, the approach may allow us to conclude that the substance is not toxic to the aquatic environment and thus the T-criteria do not apply. Hence the substance may be at the most a vPvB compound (very persistent + very bioaccumulative). Testing its inherent biodegradability and its potential bioaccumulation will exclude or confirm the respective $\mathrm{vPvB}$ characteristics; otherwise it will be advisable to substitute this substance.

Summarising, ECOSM (acronym: ECOtoxicity investigations of COSMetic ingredients) will contribute establishing an adequate assessment methodology for poorly soluble substances, promoting the use of environmentally compatible chemicals in general and in cosmetic products in particular.

\section{Project structure}

The research project milestones are embedded in five working packages (WP):

In the first place a literature research (WP 1) shall update the state of knowledge regarding the ecotoxicity testing of poorly soluble compounds. The results shall be communicated in a report and published as a review paper. In the further course of this project, the water solubility (WP 2) of selected substances will be determined according to the OECD-Guideline 105. Criteria for the selection of model substances will be: high lipophilicity $\left(\log K_{\mathrm{OW}}>6\right)$ and low volatility, narcotic mode of action, accessibility to analytical determination at low concentrations. The substances may be potential cosmetic ingredients or potential PBT substances. In order to detect influences on the solubility, the test will be performed with water, testing medium and fluvial water. The concentration of the tested substance in the water phase will be determined by appropriate analytical methods (e.g. GC-MS). Furthermore, the data will be compared with the solubility measurements by 'passive dosing'. In order to achieve the latter, development of appropriate testing systems for 'passive dosing' (WP3) is necessary. The objective is to check which 'passive-dosing method' will be best to perform aquatic biotests and if needed, to adapt the existing methods to the tests.

After the implementation of suitable test methods the aquatic ecotoxicity (WP 4) of the selected substances will be determined performing tests with algae [7], daphnids $[8,9]$ and fish eggs [10] i.e. OECD-Draft 'Fish Embryo Toxicity Test' [11] as an alternative for the acute fish toxicity test [12]. To assess possible long-term effects, a sub-lethal fish test [13] will be conducted as well as other chronic tests such as the Daphnia reproduction test and the algal growth inhibition test. Furthermore the tests shall examine whether possible effects are induced by systemic or by physicochemical impacts. This differentiation will be possible by using a ${ }^{14} \mathrm{C}$-radiolabeled model substance enabling, in addition, to investigate the exposure of daphnids and fish via food.

The metabolism of one of the selected substances in aquatic organisms and the potential of bioaccumulation will be tested in WP 5. The studies will be based on the standard bioaccumulation test with fish [14] using a radiolabelled substance. The results can be used to model the uptake and concentration in fish and to predict effects by applying the 'Critical Body Burden' concept [15].

\section{The ECOSM consortium}

The consortium conducting and accompanying the project ECOSM consists of five partners including representatives from the RWTH Aachen University, the German Cosmetic, Toiletry, Perfumery and Detergent Association, two small- to medium-sized enterprises (SMEs) and the German Federal Environment Agency (UBA).

Institute for Environmental Research (Biology V), RWTH Aachen University (Stefanie Damme, Prof. Dr. Andreas Schäffer, Prof. Dr. Hans-Toni Ratte and Prof. Dr. Henner Hollert): Literature study and experimental work in the context of a PhD thesis.

German Cosmetic, Toiletry, Perfumery and Detergent Association (IKW) Dr. Klaus Rettinger Dr. Josef Steber, Dipl.-Ing. Birgit Huber: Organisation and coordination of the industrial advisory board.

German Federal Environment Agency (Dr. Christoph Schulte): Advisory role in order to ensure that data and information meet the requirements and standards of a risk and PBT-assessment under $\mathrm{REACH}$

ECT Oekotoxikologie GmbH (Dr. Thomas Knacker and Dr. Anja Coors): Advisory role with regard to 'Good Laboratory Practice' (GLP), development of new Standard Operating Procedures (SOP), to ensure practicability of aquatic test systems adapted to 'passive dosing' methods, and introduction of the PhD student to bioaccumulation testing with fish.

Dr. Kurt Wolff GmbH and Co KG (Dr. A. Klenk): Assessment of the feasibility of the developed 'Poorly Solubles Approach' methodology and identification of potential application difficulties for SMEs.

\section{Acknowledgements}

This joint project is supported by the German Federal Environmental Foundation (DBU, Deutsche Bundesstiftung Umwelt).

\section{Author details}

${ }^{1}$ RWTH Aachen University, Institute for Environmental Research (Biology V), Worringerweg 1, 52074 Aachen, Germany ${ }^{2} \mathrm{ECT}$ Oekotoxikologie $\mathrm{GmbH}$, Böttgerstraße 2-14, 65439 Flörsheim, Germany ${ }^{3}$ German Cosmetic, Toiletry, Perfumery and Detergent Association (IKW), Mainzer Landstraße 55, 60329 Frankfurt am Main, Germany ${ }^{4}$ German Federal Environment Agency, Wörlitzer Platz 1, 06844 Dessau-Roßlau, Germany 


\section{Authors' contributions}

SKED drafting and conception of the manuscript, HTR revision and final approval, $\mathrm{HH}$ revision and final approval, AC revision and final approval, TK revision and final approval, KR revision and final approval, CS revision and final approval and AS project leader, supervision, revision and final approval. All authors read and approved the final manuscript.

\section{Competing interests}

The authors declare that they have no competing interests.

Received: 31 May 2011 Accepted: 8 September 2011

Published: 8 September 2011

\section{References}

1. Brooks BW, Huggett DB, Boxall ABA: Pharmaceuticals and personal care products: research needs for the next decade. Environ Toxicol Chem 2009, 28:2469-2472.

2. Tolls J, Muller M, Willing A, Steber J: A new concept for environmental risk assessment of poorly water-soluble compounds and its application to consumer products. Integr Environ Assessm Managem 2009, 5:374-378.

3. De Wolf W, Siebel-Sauer A, Lecloux A, Koch V, Holt M, Feijtel T, Comber M, Boeije G: Mode of action and aquatic exposure threshold of no concern. Environ Toxicol Chem 2005, 24:479-485.

4. Könemann H: Quantitative structure-activity relationships in fish toxicity studies. Part 1: Relationship for 50 industrial pollutants. Toxicology 1981, 19:209-221.

5. Verhaar HJM, van Leeuwen CJ, Hermens JLM: Classifying environmental pollutants. Part 1: Structure-activity relationships for prediction of aquatic toxicity. Chemosphere 1992, 25:471-491.

6. EC: Regulation (EC) No. 1907/2006 of the European Parliament and of the Council of 18 December 2006 concerning the Registration, Evaluation, Authorisation and Restriction of Chemicals (REACH), establishing a European Chemicals Agency, amending Directive 1999/45/EC and repealing Council Regulation (EEC) No. 793/93 and Commission Directives 91/155/EEC, 93/67/ EEC, 93/105/EC and 2000/21/EC 2006.

7. OECD: OECD guidelines for the testing of chemicals. Section 2: effects on biotic systems test no. 201: freshwater alga and cyanobacteria, growth inhibition test Paris: Organisation for Economic and Cooperative Development; 2006.

8. OECD: OECD guidelines for the testing of chemicals. Section 2: effects on biotic systems test no. 202: Daphnia sp., acute immobilisation test Paris: Organisation for Economic and Cooperative Development; 2004.

9. OECD: OECD guidelines for the testing of chemicals. Section 2: effects on biotic systems test no. 211: Daphnia magna reproduction test Paris: Organisation for Economic and Cooperative Development; 2008.

10. DIN EN ISO 15088T6: Wasserbeschaffenheit-Bestimmung der akuten Toxizität auf Zebrafisch-Eier (Danio rerio) (ISO 15088:2007) Deutsche Fassung EN ISO 15088:2008; 2009.

11. OECD-Draft: OECD guidelines for the testing of chemicals. Section 2: effects on biotic systems. draft proposal for a new guideline. fish embryo toxicity (FET) Test Paris: Organisation for Economic and Cooperative Development; 2006.

12. OECD: OECD guidelines for the testing of chemicals. Section 2: effects on biotic systems test no. 203: fish, acute toxicity test Paris: Organisation for Economic and Cooperative Development; 1992.

13. OECD: OECD guidelines for the testing of chemicals. Section 2: effects on biotic systems test no. 210: fish, early-life stage toxicity test Paris: Organisation for Economic and Cooperative Development; 1992.

14. OECD: OECD guidelines for the testing of chemicals. Section 2: effects on biotic systems test no. 305: bioconcentration: flow-through fish test Paris: Organisation for Economic and Cooperative Development; 1996.

15. McElroy AE, Barron MG, Beckvar N, Kane Driscoll SB, Meador JP, Parkerton TF, Preuss TG, Steevens JA: A review of the Tissue residue approach for organic and organometallic compounds in aquatic organisms. Integrated Environmental Assessment and management 2010, 7:50-74.

doi:10.1186/2190-4715-23-30

Cite this article as: Damme et al:: ECOSM-a new joint project for assessing environmental risks of poorly soluble compounds used in cosmetics-project presentation. Environmental Sciences Europe 2011 23:30.

\section{Submit your manuscript to a SpringerOpen ${ }^{\mathcal{O}}$ journal and benefit from:}

- Convenient online submission

- Rigorous peer review

- Immediate publication on acceptance

- Open access: articles freely available online

- High visibility within the field

- Retaining the copyright to your article

Submit your next manuscript at $\gg$ springeropen.com 